\title{
Controlled Release Tablet Dosage Form
}

National Cancer Institute

\section{Source}

National Cancer Institute. Controlled Release Tablet Dosage Form. NCI Thesaurus. Code C69025.

A tablet designed to release active and/or inert ingredient(s) at a controlled rate. 